\title{
Nursing identity and patient-centredness in scholarly health services research: a computational text analysis of PubMed abstracts 1986-2013
}

Erica Bell ${ }^{1{ }^{\uparrow}}$, Steve Campbell ${ }^{*^{*}}$ and Lynette R Goldberg ${ }^{1 \dagger}$

\begin{abstract}
Background: The most important and contested element of nursing identity may be the patient-centredness of nursing, though this concept is not well-treated in the nursing identity literature. More conceptually-based mapping of nursing identity constructs are needed to help nurses shape their identity. The field of computational text analytics offers new opportunities to scrutinise how growing disciplines such as health services research construct nursing identity. This paper maps the conceptual content of scholarly health services research in PubMed as it relates to the patient-centeredness of nursing.

Methods: Computational text analytics software was used to analyse all health services abstracts in the database PubMed since 1986. Abstracts were treated as indicative of the content of health services research. The database PubMed was searched for all research papers using the term "service" or "services" in the abstract or keywords for the period 01/01/1986 to 30/06/2013. A total of 234,926 abstracts were obtained. Leximancer software was used in 1) mapping of 4,144,458 instances of 107 concepts; 2) analysis of 106 paired concept co-occurrences for the nursing concept; and 3) sentiment analysis of the nursing concept versus patient, family and community concepts, and clinical concepts.
\end{abstract}

Results: Nursing is constructed within quality assurance or service implementation or workforce development concepts. It is relatively disconnected from patient, family or community care concepts.

Conclusions: For those who agree that patient-centredness should be a part of nursing identity in practice, this study suggests that there is a need for development of health services research into both the nature of the caring construct in nursing identity and its expression in practice. More fundamentally, the study raises questions about whether health services research cultures even value the politically popular idea of nurses as patient-centred caregivers and whether they should.

Keywords: Nursing identity, Health services research, Patient-centredness, Computational linguistics

\section{Background}

\section{Defining identity}

Identity has been a strong preoccupation of philosophy and social science enquiry for hundreds of years, both individual identity and collective or group identity. This is because identity is thought to shape individual and social behaviour [1-4]. One of the most influential theories

\footnotetext{
* Correspondence: Steven.Campbell@utas.edu.au

${ }^{\dagger}$ Equal contributors

Deceased

${ }^{2}$ School of Health Sciences, University of Tasmania, Locked Bag 1322,

Launceston, Tasmania 7250, Australia

Full list of author information is available at the end of the article
}

of identity comes from the work of French philosopher Foucault on whom the Library of Congress holds over 10,000 items. Foucault defined individual and collective identity as a social construct that is created in language. In Foucault's writings, historical and social processes work to actively create these identities, operating sometimes subliminally through particular kinds of knowledge to shape what assumptions people accept about themselves and others [5,6]. An example of this, important in this study, is how nursing and patient care have been constructed over the last 25 years in the discipline of health services research, as captured in a particular database PubMed.

\section{Biomed Central}

(c) 2015 Bell et al.; licensee BioMed Central. This is an Open Access article distributed under the terms of the Creative Commons Attribution License (http://creativecommons.org/licenses/by/2.0), which permits unrestricted use, distribution, and reproduction in any medium, provided the original work is properly credited. The Creative Commons Public Domain Dedication waiver (http://creativecommons.org/publicdomain/zero/1.0/) applies to the data made available in this article unless otherwise stated. 
In discursive psychology, which builds on the work of Foucault, identity is also understood to be about how language is used to create and position the self in relation to the world [7-9]. This second aspect of identity is also important to this study. In this study, the focus is upon how nursing identity is positioned in relation to other concepts in the discipline of health sciences as reflected in PubMed [8,9]. Nursing is seen as positioned in the language of health sciences research in ways that create particular kinds of "story-lines" that suggest professional attributes [7-9]. Of particular interest in this study is how this identity may be measured, and whether and how it offers insights into the quality agenda in healthcare in which patient-centred care is perceived as critical.

\section{Definitions of identity in the nursing identity literature}

Identity has also been defined extensively in the nursing literature. The body of literature about nursing identity is a growing one, albeit one that sometimes lacks methods and data to support its hypotheses. For the period $1^{\text {st }}$ January 2008 to $5^{\text {th }}$ of September 2013, a total of 505 papers are listed in PubMed including the terms "nursing" OR "nurse" OR "nurses" AND "identity." A recent review of nursing identity has made a distinction between the professional self-identity of nurses and the public identity or image of nursing [10]. The public image has been described as partly created by default by nurses themselves who have not always participated in public discourse. The professional self-identity of nurses is a complex construct that includes, but is not limited to, this public image, work contexts, work values, education and social or cultural values [10]. Specialist nurses such as mental health nurses have been found to have an identity comprised of a cluster of "identity characteristics" [11]. The acquisition of a nursing professional identity through processes of "professional socialisation" is known to be complex and multifaceted and is the focus of a substantial part of the nursing identity literature [12]. Nursing identity has also been described as a measureable self-concept that can be "manipulated" to help improve nursing retention, although sound psychometrically validated instruments are needed $[13,14]$.

\section{The importance of nursing identity to the quality of healthcare}

Nursing identity is seen as having a fundamental importance for the quality of healthcare. Nursing identity has been strongly linked to student retention in nursing programs [15]. Recruitment and retention problems in, for example, mental health nursing have been linked to the ambiguity of the mental health nursing role [16]. Nursing identity has also been constructed as important to whether and how nurses expand their leadership roles and skills, with positive implications for patient care $[17,18]$. Ideas about professional identity and roles shape nursing service management in, for example, the contested area of optimum skill mix and nursing staffing levels for patient outcomes [19]. Nursing identity has also been seen as important to growing collaborative research involving academic and practice settings, which in turn are perceived as helping to improve the quality of patient care [20]. Nursing identity has even been shown to shape the extent to which nurses support healthcare reform affecting their roles [21].

\section{Patient-centred care and its importance to nursing identity}

One of the most important constructs in the popular and scholarly literature about nursing identity is "patient-centred care." Yet it is also one of the most contested constructs. A recent review found that nurses, physicians and managers all used the discourse of "patient-centred care" to suggest that their own professional group was patient-centred while other professional groups were not [22]. In the language of policy-makers, "patientcentredness" may be a lever for achieving change in professional attitudes, as in the United Kingdom's public debate about graduate nurses being "too posh to wash" or deliver essential nursing care $[23,24]$. In such a politicised debate in the media, problems with nursing recruitment, as well as nursing care, have been seen as being caused by the increasingly academic nature of nurse education and the specialisation of the nursing professions [25]. Yet in the nursing literature, the role of "essentialist caring values" is often described as important to the future of nursing [26].

However, patient care as a component of professional identity-the degree to which caring is seen as a part of nursing professional identity-has had relatively less attention in the contemporary nursing identity literature. Caring in nursing is articulated as being linked to taskoriented approaches to nursing and being grounded in the relational empathy and connection between the professional nurse and the patient [27]. A "dimensional analysis" of patient-centred care describes it as including an eclectic range of elements, from providing a comforting room design to emotional support to attention to individualised meals to supports for patient decision-making [28]. The authors of this analysis considered 69 papers published between 2000-2006 and found that the common themes of patient-centred care involved complex and sustained attention in nurse-patient interactions to alleviating vulnerabilities, as well as therapeutic engagement based on a knowledge of, and relationship with, the patient [28]. Thus, in the nursing literature, "patient-centred" care has a strongly individual patient-nurse meaning.

Beyond the literature on nursing identity as such, nursing theory and knowledge development have traditionally 
included a strong discourse of "caring science scholarship" [29]. The construct of caring is a multi-faceted one that has been the subject of different conceptualisations and theoretical frameworks since the 1990s at least [30-33]. Watson has described the dominant construct of caring as involving emotional and physical labour components, or expressive and instrumental elements, and argued that such intuitive constructs can be operationalized and measured [34,35]. The construct has been most notably applied using instruments such as the Caring Dimensions Inventory to measure student perceptions of caring as having both psycho-social and professional/technical dimensions [34-37]. By 2001, 16 such instruments were reviewed in a monograph on assessing and measuring caring [38]. Yet there is a perceived divide between qualitative and quantitative approaches to researching caring [35] and caring research has been criticised for failing to yield to scientific advances in knowledge [39].

\section{Perceived threats to the patient-centredness of care and the quality of healthcare}

Despite the importance of "patient-centred" care to nursing identity, it is clear that it is perceived as being under threat in ways that threaten the quality of healthcare. For example, in hospital settings, studies have suggested that only around a third of the time of different nursing professionals is spent on direct patient care, despite the growing complexity of these direct care needs: admission and assessment, hygiene and patient/family interaction, medication and IV administration and procedures [40]. Concerns about the deregulation of direct patient care in, for example, areas of growing care complexity such as aged care, position a declining valuing of direct patient care and care workers as part of the problem of care quality [41]. The whole evidence-based practice movement has been seen as devaluing the complex interpersonal element of the caring components of nursing [42]. That is, the emphasis on evidence-based practice, outcomes-based practice, and quantifiable efficiencies has been seen as ultimately threatening the fundamental "caring" strengths of nursing identity and practice, and the quality and safety agenda [43]. Industrially, "caring" in nursing identity is also seen as under threat by new regimes of economic management, characterised by widespread cuts to services and staff reductions [44].

This is not to argue that patient-centredness has an unproblematic relationship to patient outcomes. The evidence is mixed regarding the efficacy of patient-centredness as a style of doctor-patient communication [45]. The asymmetry between doctor and patient is thought to have deep and even possibly justified roots in the clinical authority of the doctor [45]. However, as the foregoing discussion demonstrates, the nursing literature has defined patientcentredness far more broadly: in terms of tasks of caring and verbal and non-verbal interaction. "Patient-centeredness" has deep roots in the whole identity of the nursing profession itself in which a nurse has a pastoral authority for broader patient health and well-being. In a context in which it is known that health outcomes are shaped by wider determinants of health, it seems likely that 1 ) a narrow definition of patient-centredness will not achieve real changes in patient outcomes, and 2) the patient outcomes of a broader definition of patient-centredness consistent with nursing caring scholarship will continue to be difficult to measure.

Notwithstanding, it is certain that ideas about nursing identity and patient-centred care will continue to shape public debate and healthcare quality agendas. For example, both the UK's Essence of Care [46] and Australia's Essentials of Care [47] emphasise a re-establishment of the traditional direct care roles of nurses. Underlying such debates is an uneasiness about the relevance of new nursing identities, in a context in which a disconnect between the disciplinary mission of nursing and its constituent patient communities is known to lead to the failure of health programmes [48].

\section{The importance of health services research to constructing nursing identity in the $21 \mathrm{stC}$}

The current study explores the construction of nursing identity from another perspective-that of research evidence, specifically health services research. The discipline of health services research is a particularly important field in which to examine nursing identity because it delivers the evidence that potentially shapes practice in health services. Health sciences research will increasingly be under pressure to deliver service benefits, through the emphasis on translational research of such United States-based agencies as the Institute of Medicine, Agency for Healthcare Research and Quality, and National Institutes of Health. The entire translational research movement, originally about better articulation of research benefits from the science laboratory "bench" to clinical practice "bedside" $[49,50]$ has developed over the last quarter of a century into new sub-disciplines of health research ensuring that health sciences research also includes health services research [51].

Accordingly, this study aims to explore to what extent the emerging discipline of health services research has positioned nurses as patient caregivers over the last quarter of a century in which over 200,000 papers in this discipline have been published. As such, this paper responds to calls in a recent review of nursing identity for more conceptually-based mapping of nursing identity constructs, capturing the subtlety of changes over time [13]. It also responds to the need for more information for nurses that can help them reflect on, and shape, the construction of their own identity, including patient- 
centredness, particularly given its importance in healthcare reform policy, nursing education and training, and care efficacy $[10,52]$.

\section{Machine-driven text analytics}

The size of the corpus of abstracts in PubMed relevant to health services is prohibitive for traditional manual methods of qualitative analysis. However, automated "natural language processing" or "computational linguistics" - the methods that inform the software used in this study - has developed over the last 30 years to offer ways of handling such unstructured datasets [53]. Natural language processing can be described as a diverse range of automated computational techniques for analysing and representing language. It underpins technological innovations such as Google and IBM's Watson, as well as Apple's Siri [54]. This section does not reproduce the content of reviews of the field published elsewhere [54], instead focussing on literature offering examples of applications in the health sciences and the justification for our choice of Leximancer software.

As of 15 April there were only 1,034 journal papers listed in the database PubMed with the terms "computational linguistics," "natural language processing," or "text analytics" in the title or abstract, 655 of which were published since 2008. These suggest that, in health, applications have been diverse and include: 1) exploration of theories in the light of social media [55];2) analyses of clinical texts for the purposes of classification [56], symptom description [57] and diagnosis [58], the analysis and prediction of patient outcomes $[59,60]$ and evaluation of the extent of utilisation of evidence in health practice [61]; 3 ) the analysis of healthcare experiences and behaviours using popular media such as YouTube [62]; and 4) clinical decision support [63]. This study takes a socio-cultural perspective, focussing on the extent to which patientcentred nursing is under-represented in the discipline of health services as represented in the PubMed database and as such may be described as a form of "evidence surveillance." In this study, software associated with natural language processing is used to explore a theoretical construct - nursing professional identity as it relates to patient-centredness in the PubMed corpus.

It is acknowledged that those wanting to learn how to do natural language processing (NLP) can access the open source Natural Language Toolkit (version $2.0 \mathrm{http}: / / \mathrm{www}$. nltk.org) using Python programming language (version 2.7, http://www.python.org) [64]. However, not all researchers will be able to become proficient computer programmers or have the resources to access computer programmers. Some researchers may also choose to use high quality standardised software products developed by advanced programmers, particularly for complex procedures such as concept mapping and sentiment analysis, to help ensure standardised results that are supported by detailed manuals and (ideally) technical validity studies. For these researchers we suggest consideration of "text analytics" software available on the market, designed using the methods of NLP. A summary of these "text analytics" products is available by market analysts [64] and there are also digital libraries available at http:// dirtdirectory.org/.

The software package Leximancer [65], originally created at the University of Queensland in Australia, includes two key functions-concept mapping and sentiment analysis-that are fairly standard in the field. Leximancer compares favourably with other products listed in the Hurwitz report [64] when criteria such as scholarly literature modelling its application, cost, installation and technical running problems and support, as well as user friendliness, are considered. We have tried and tested other products including the costly IBM SPSS Modeller Premium software (Version 15.0, http://www.spss.com.hk/ software/modeler/). We have found that other products do not have the scholarly validity study [66] or body of published scholarly applications supporting Leximancer's concept analysis and sentiments analysis procedures [67-74]. However, there has not yet been an application of Leximancer to the corpus of health service research abstracts, although the software offers a novel technique for mapping this large language dataset. Notwithstanding, the software suffers from the limitations of other NLP approaches: a lack of "real world" and common-sense knowledge about the contextualised meanings of words.

Leximancer is Bayesian-based software that "learns" from an uploaded dataset that it reads iteratively. For concept mapping, Leximancer creates a network of concepts defined in "text blocks" of about a paragraph in size, normally three sentences, but defined by a process of machine learning (described below). In Leximancer, a text block is the unit of analysis. An abstract may contain one or more text blocks and one text block may contain one or more concepts, just as a sentence can contain more than one concept. In sentiment analysis, Leximancer maps the frequency and co-occurrence of concepts with an in-built thesaurus of sentiment terms (negative versus positive). In more technical terms, Leximancer is described as an unsupervised approach to transforming lexical co-occurrence information from language data into semantic patterns. There are two kinds of co-occurrence information extraction in Leximancer's automated procedures-semantic and relational-each with a different algorithm [66]. These algorithms employ nonlinear dynamics and machine learning as summarised in the following technical overview:

A unified body of text is examined to select a ranked list of important lexical terms on the basis of word frequency and co-occurrence usage. These terms then seed 
a bootstrapping thesaurus builder, which learns a set of classifiers from the text by iteratively extending the seed word definitions. The resulting weighted term classifiers are then referred to as concepts. Next, the text is classified using these concepts at a high resolution, which is normally every three sentences. This produces a concept index for the text and a concept co-occurrence matrix. By calculating the relative co-occurrence frequencies of the concepts, an asymmetric co-occurrence matrix is obtained. This matrix is used to produce a twodimensional concept map via a novel emergent clustering algorithm. The connectedness of each concept in this semantic network is employed to generate a third hierarchical dimension, which displays the more general parent concepts at the higher levels [66].

This means that, for example, for the concept of nursing, Leximancer works by merging similar terms e.g. nurses, nursing, nursing assistant. The classifications of nursing will be developed from the text: if "physician's assistant" is used synonymously with "nurse" the term may be learned by Leximancer and integrated into a nursing concept. The analyst also scrutinises the output at different stages to identify the concept seed words and the thesaurus terms Leximancer produces. Terms that are obviously the same can be merged manually. This demonstrates an important feature of Leximancer: it is automated but also features multiple interactive data viewing windows that allow analyst scrutiny and intervention.

The current study is therefore not a study of types of research but rather of concepts in the corpus of abstracts about health services in PubMed. The advantage of a concept analysis is precisely that it does not involve a valuing or critiquing of research using familiar typologies of research such as quantitative or qualitative research or any other way of describing research methods or research disciplines. Rather, this study measures the prevalence of particular concepts that cut across these different types of research. An example of a text block classified by Leximancer under the nursing concept, and tending to emphasise nursing service structures rather than the immediate pastoral dimensions of caring in nursing, is as follows:

PMID: 3228766

409. Can J Nurs Adm. 1988 Oct;1(3):16-8.

Ambulatory care nursing. A new approach.

McMaster DC, Greer PM, Beanlands HE.

This article describes one hospital's experience with integrating inpatient and outpatient nursing services. Nursing services integration enabled nursing management to combine the nursing resources allocated to the inpatient and outpatient components of a clinical service under the direction of one nurse manager. This new and creative approach was implemented in thirteen clinical services at the Victoria General Hospital, Halifax. This organizational structure was considered to be an effective approach for managing ambulatory care nursing services. The introduction of integration facilitated a change in the ambulatory care nursing role. It also provided for increased continuity of patient care and afforded nurses the opportunity to practice in another setting. Nursing services integration is considered a more effective approach for managing nursing resources.

Further technical details about Leximancer analysis are available in the validity study [66].

\section{Methods}

In a sentence, concept mapping in Leximancer is about understanding semantic relationships within the entire network of concepts that exist in a language dataset. Sentiment analysis is about understanding the extent to which a concept is semantically proximate to sentiment words generally, as well as the extent to which a concept is semantically proximate to positive versus negative words. In terms of our theoretical framework, we agree that the definition of a concept used in concept mapping is itself the result of epistemologies [75].

Concept mapping and content analysis have traditionally been defined by theoretical frameworks, such as those of Saussure [76], which assume human, manual methods of textual analysis. However, while Leximancer is a machinebased method it also has certain embedded epistemological assumptions, namely that language is an artifact of human behaviour that can be measured as a semantic network, albeit only as a starting point for qualified interpretation and further data mining. We do not believe that the conflict in concept mapping approaches between the analytic school and the postmodern deconstructionist one [75] - a conflict essentially between the study of formal structuralist approaches to language such as linguistics, versus the deconstruction of texts associated with philosophers such as Derrida [77] — is at all useful. Rather, we believe that machine-based approaches based on the field of natural language processing, as used in this study, need to be framed by theoretical constructs - in this study from the caring and identity literature - and include a section on the limitations of machine-based findings.

\section{Research questions}

The research questions were 'How is content about nursing, especially as it relates to patient-centredness, related to other content in health services research abstracts in PUBMED?' and 'What are the implications for understanding whether patient-centred nursing is underrepresented in the health services literature?'

\section{Data sources}

The study was limited to how health services research is constructed in PubMed, an authoritative database of 22 
million citations, including from MEDLINE, maintained by the National Center for Biotechnology Information at the United States' National Library of Medicine, based at the National Institutes of Health. As such, the study was designed to be an analysis of how health services research constructs nursing identity and patient-centredness in a particular database - PubMed - not an exhaustive study of all scholarly health services literature.

The method involved treating PubMed abstracts as indicative evidence of the content of health services research in this database. The database PubMed was searched for all research papers using the term "service" or "services" in the abstract or keywords for the period $01 / 01 / 1986$ to $30 / 06 / 2013$. The downloaded abstracts were added to a SQLite database used to generate CSV files with abstracts batched in three-year periods (except for 2013 which was batched from 1/1/13-31/6/13). Manual checks of data consistency were conducted that also removed duplicate abstracts. This involved an iterative process in which automated searches of duplicates were complemented by manual spot checks and took an estimated six weeks of full-time work. A total of 234,926 abstracts were obtained. Table 1 provides the counts of abstracts for each period of the analysis. The period 1986-1988 was selected as the first period of the study to allow the study to cover a span of at least a quarter of a century.

\section{Analytical procedure}

The analysis proceeded using three standardised stages that involved quantification of the conceptual content of the abstracts using Leximancer software [65].

\section{Stage 1: concept mapping}

This stage obtained a conceptual overview of the health service abstracts. Leximancer was used to obtain frequency and co-occurrence statistics for all concepts in the abstracts, as well as visualisations of these data in a concept map. This involved some "concept cleaning" by

Table 1 Counts of abstracts, by year

\begin{tabular}{ll}
\hline Jan-June 2013 & $\mathbf{8 9 8 3}$ \\
\hline $2010-2012$ & 50638 \\
$2007-2009$ & 39359 \\
$2004-2006$ & 32298 \\
$2001-2003$ & 25357 \\
$1998-2000$ & 22641 \\
$1995-1997$ & 19342 \\
$1992-1994$ & 15976 \\
$1989-1991$ & 12887 \\
$1986-1988$ & 7445 \\
Total & 234926 \\
\hline
\end{tabular}

the authors in which only irrelevant words that related to the common structural features of abstracts such as "conclusions" and "method" were discarded as mapping concepts. Country names such as USA were not included as mapping concepts as country-based themes were beyond the scope of the study. The concept map was designed to show what concepts were found, and their proximity to one another, in the larger dataset of 234,926 abstracts for health services research. This stage mapped a total of 4,144,458 instances of 107 concepts in $1,311,805$ text blocks of about a paragraph in size. It also suggested typical connections (or common storylines) between the nursing concept obtained and multiple other concepts in the health services abstracts.

\section{Stage 2: nursing concept analysis}

In this stage, the 54,507 instances of the nursing concept identified in Stage 1 were analysed for immediate associations with all other concepts in the dataset. A total of 106 types of paired co-occurrences for the nursing concept were extracted and analysed. Supporting counts and likelihood of paired co-occurrences were obtained, as well as likelihoods for the nursing concept occurring in the different sub-periods of the analysis.

\section{Stage 3: sentiment analysis}

This stage mapped how sentiment about nursing compared with sentiment about patient, family and community concepts as well as with more clinical concepts in the health service literature. Frequency and extent of sentiment associations with the nursing concept were compared with the sentiment associations of nine other selected concepts: clinical, community, family, hospital, medical, patients, prevention, social, treatment. The inbuilt thesaurus of positive and negative sentiment words in Leximancer was used to analyse changes over time in negative and positive sentiment associated with these 10 selected concepts. A visual representation of sentiment associations with nursing versus sentiment associations with selected other concepts, by sub-period, was obtained using a quadrant.

The process of producing the final concept map is stochastic, so the stability of findings was tested by running the data three times, consistent with the account of stability issues provided in the technical validity study [66]. Manual checks were also performed of logs of text blocks informing the software output reported here. The multiple data viewing windows available in Leximancer also facilitated iterative manual checks on the findings. For example, for each concept, the analyst can view all text blocks in isolation and also in context in the original datafile, as well as log and further analyse those individual concepts. 


\section{Results}

\section{Concept map}

Figure 1 maps all 4,144,458 instances of the 107 concepts found in 1,311,805 text blocks of about a paragraph in size. The concept map should be considered as a spatial representation of the semantic proximity of these 107 concepts. The location of a concept and its time period is determined by its placement relative to all other concepts [65]. The grey lines suggest the more typical semantic pathways or "storylines" involving multiple concepts (not necessarily the most frequent pairs of concepts). The size of the spheres is designed to accommodate the spatial semantic placement of the concepts, i.e. the size of the spheres denotes these boundaries only. The size of a grey dot indicates the extent to which that concept co-occurs with all other concepts. This overall co-occurrence is different from the paired co-occurrences examined later which are about immediate relationships between two concepts - not the relatedness of one concept to all other concepts in a dataset. The map is designed to offer a bird's eye view of the data, meant to be supplemented by the supporting data in the tables.

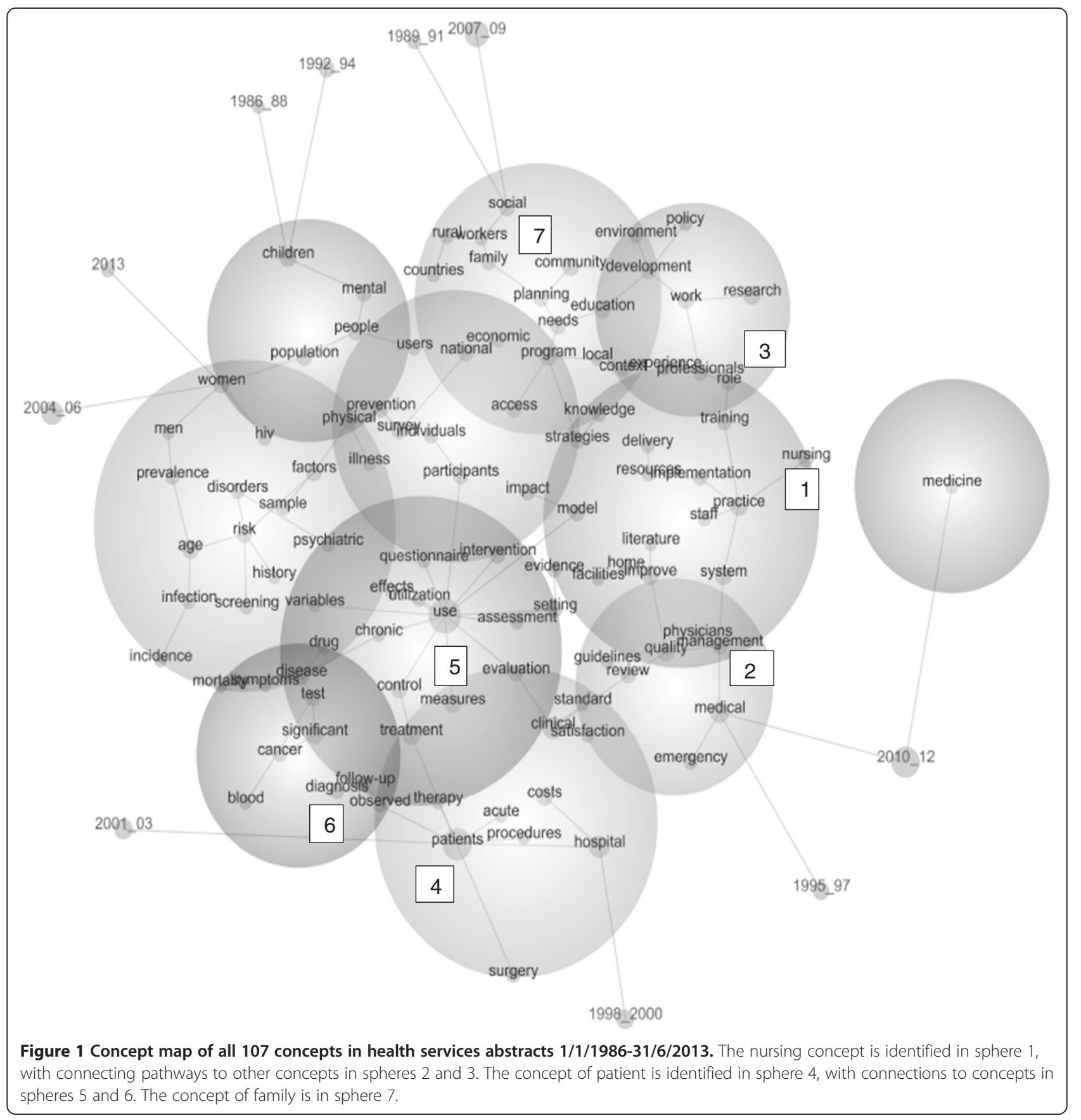


Figure 1 suggests that the nursing concept (in sphere 1) is typically connected to these storylines:

Nursing $\rightarrow$ practice and, through "practice," branching out to multiple other storylines (like the spokes of a wheel around the practice concept), such as system $\rightarrow$ management (moving into sphere 2) $\rightarrow$ quality OR staff OR implementation (in sphere 1 ) $\rightarrow$ resources $\rightarrow$ delivery OR training $\rightarrow$ role (moving into sphere 3 ) $\rightarrow$ professionals.

This suggests that nursing has tended to be constructed by the health service research within quality assurance or service implementation or workforce development concepts. It suggests that service research does not tend to construct nursing in terms of broader patient, family or community care storylines.

The location of the patient concept in sphere 4 suggests health service research constructs patients within the following typical storylines to do with biomedical interventionist, cost utility and research measurement storylines (again, moving round the concept of patient like the spokes of a wheel):

Patients $\rightarrow$ therapy $\rightarrow$ treatment (moving into sphere 5) $\rightarrow$ control $\rightarrow$ use

Patients $\rightarrow$ acute (within sphere 4)

Patients $\rightarrow$ procedures $\rightarrow$ hospital $\rightarrow$ costs (within sphere 4)

Patients $\rightarrow$ surgery (within sphere 4 )

Patients $\rightarrow$ observed $\rightarrow$ diagnosis (moving into sphere 6)

The concept map in Figure 1 suggests also that family and community concepts, like the patient concept, are relatively less well connected to the nursing concept. Both the family and community concepts (in sphere 7) are linked (in separate spokes) only to the planning $\rightarrow$ needs $\rightarrow$ program concepts. This suggests that when these concepts occur they typically do so within quite singular planning storylines.

Table 2 gives counts of instances of all of the 107 concepts (bearing in mind a text block can contain more than one instance of a concept) and relevance of that concept. "Relevance" is the percentage of text blocks in which that concept appears, relative to the most frequent concept entity on the map, i.e., relevance is the count of a concept divided by the single highest count value which always therefore has a relevance of $100 \%$. Therefore it is the relativities between the concepts that are of interest. Table 2 suggests that the storylines about nursing within the health service abstracts need to be understood in the context of how service research constructs itself. The most common concepts in the service research are intervention use (which includes words to do with utility or usefulness), clinical response and clinical setting concepts (such as "hospital," "medical," and "clinical") - concepts with $69 \%$ to $29 \%$ relevance. "Patients" is the second most relatively common concept in Table 2, notwithstanding its distance from the nursing concept in Figure 1. Table 2 also shows the community concept is actually one per cent more common than nursing, whatever its proximity to the nursing concept in Figure 1.

\section{The nursing concept}

Table 3 provides the counts of all 54,507 instances of the nursing concept for each sub-period of the analysis from 1986 to June 2013. The likelihood percentage gives the percentage of all text blocks in a sub-period that contain the nursing concept. It suggests that, regardless of increases in the amount of health services research suggested by Table 1, the proportional share of all research that is about nursing is actually a little lower in the last five years (2007-June 2013) than in the period just before (2001-2006) or indeed even from 1995-2000. That is, if Figure 1 and Table 2 suggest nursing has not been central to patient, family or community care storylines in the health services research, Table 4 suggests that the nursing concept itself has not been increasing in the growing field of health service literature.

Table 4 gives the counts and likelihood of occurrence of all 106 concepts paired with the nursing concept in the health service abstracts (in contrast to the dominant storylines across multiple concepts suggested by Figure 1). The likelihood percentage gives the percentage of all text blocks in a pair that contain the nursing concept. For example, given we have selected the nursing concept, the related concept list includes a concept called "satisfaction" that occurs 1,507 times and has a likelihood score of $9 \%$. The likelihood percentage of $9 \%$ means that $9 \%$ of all the text blocks with the "satisfaction" concept also contain the nursing concept. This statistic is designed to complement the count statistics so both directions of conditional probability are given [78]. Of course, given that we are dealing with the likelihood that any one paired concept will also contain the nursing concept, the likelihood percentages of all these 106 concepts will not add up to $100 \%$.

Table 4 therefore suggests that aged care homes is most commonly paired with nursing. Manual checks were conducted to ensure that the "home" concept was overwhelmingly about aged care homes not home nursing. The next two most common nursing paired cooccurrences are with nursing staffing and nursing role concepts. Table 4 suggests that, when the patient concept occurs, it is paired with the nursing concept only $5 \%$ of the time in the service abstracts. When the community concept occurs, it is paired with the nursing concept only $8 \%$ of the time. The family concept is paired with the nursing concept only $6 \%$ of the time. In contrast, the least common paired co-occurrences for the nursing concepts - those listed as occurring in $2 \%$ of the text blocks where the paired concept occurs, are more clinical disease and diagnostic concepts, as well as more technical epidemiological research concepts such as "prevalence" 
Table 2 Counts and relevance of instances of concepts

\begin{tabular}{|c|c|c|c|c|c|}
\hline Concept & Count & Relevance & Concept & Count & Relevance \\
\hline use & 217339 & $69 \%$ & cancer & 31290 & $10 \%$ \\
\hline patients & 194810 & $62 \%$ & surgery & 30991 & $10 \%$ \\
\hline hospital & 110504 & $35 \%$ & implementation & 30803 & $10 \%$ \\
\hline medical & 91944 & $29 \%$ & individuals & 30377 & $10 \%$ \\
\hline clinical & 91823 & $29 \%$ & drug & 29179 & $9 \%$ \\
\hline treatment & 73690 & $23 \%$ & resources & 28540 & $9 \%$ \\
\hline research & 71312 & $23 \%$ & professionals & 28134 & $9 \%$ \\
\hline children & 67849 & $22 \%$ & home & 28112 & $9 \%$ \\
\hline practice & 65274 & $21 \%$ & diagnosis & 28008 & $9 \%$ \\
\hline program & 62746 & $20 \%$ & hiv & 26293 & $8 \%$ \\
\hline community & 57096 & $18 \%$ & disorders & 26159 & $8 \%$ \\
\hline system & 56844 & $18 \%$ & countries & 25570 & $8 \%$ \\
\hline age & 56635 & $18 \%$ & assessment & 25055 & $8 \%$ \\
\hline improve & 56078 & $18 \%$ & strategies & 25049 & $8 \%$ \\
\hline people & 55593 & $18 \%$ & prevalence & 24919 & $8 \%$ \\
\hline significant & 55159 & $17 \%$ & screening & 24412 & $8 \%$ \\
\hline women & 54752 & $17 \%$ & delivery & 23784 & $8 \%$ \\
\hline nursing & 54507 & $17 \%$ & staff & 22767 & $7 \%$ \\
\hline quality & 54136 & $17 \%$ & therapy & 22618 & $7 \%$ \\
\hline population & 53829 & $17 \%$ & evidence & 22468 & $7 \%$ \\
\hline disease & 51932 & $16 \%$ & mortality & 22115 & $7 \%$ \\
\hline factors & 51551 & $16 \%$ & knowledge & 22008 & $7 \%$ \\
\hline costs & 51029 & $16 \%$ & utilization & 21967 & $7 \%$ \\
\hline medicine & 50018 & $16 \%$ & physicians & 21909 & $7 \%$ \\
\hline needs & 49194 & $16 \%$ & standard & 21772 & $7 \%$ \\
\hline mental & 49072 & $16 \%$ & questionnaire & 21710 & $7 \%$ \\
\hline measures & 48653 & $15 \%$ & infection & 21618 & $7 \%$ \\
\hline risk & 48644 & $15 \%$ & rural & 20922 & $7 \%$ \\
\hline control & 47938 & $15 \%$ & effects & 20750 & $7 \%$ \\
\hline national & 47507 & $15 \%$ & symptoms & 18978 & $6 \%$ \\
\hline social & 46583 & $15 \%$ & psychiatric & 18620 & $6 \%$ \\
\hline management & 46441 & $15 \%$ & physical & 18266 & $6 \%$ \\
\hline education & 46276 & $15 \%$ & users & 17903 & $6 \%$ \\
\hline work & 45608 & $14 \%$ & local & 17609 & $6 \%$ \\
\hline survey & 44941 & $14 \%$ & observed & 17356 & $6 \%$ \\
\hline intervention & 44208 & $14 \%$ & environment & 17297 & $5 \%$ \\
\hline participants & 43618 & $14 \%$ & facilities & 17295 & $5 \%$ \\
\hline model & 42407 & $13 \%$ & procedures & 17166 & $5 \%$ \\
\hline review & 41351 & $13 \%$ & acute & 16859 & $5 \%$ \\
\hline access & 40580 & $13 \%$ & workers & 16638 & $5 \%$ \\
\hline prevention & 40396 & $13 \%$ & chronic & 16031 & $5 \%$ \\
\hline development & 39687 & $13 \%$ & satisfaction & 16010 & $5 \%$ \\
\hline test & 39575 & $13 \%$ & men & 15957 & $5 \%$ \\
\hline
\end{tabular}


Table 2 Counts and relevance of instances of concepts (Continued)

\begin{tabular}{|c|c|c|c|c|c|}
\hline evaluation & 36279 & $12 \%$ & literature & 15520 & $5 \%$ \\
\hline planning & 36084 & $11 \%$ & follow-up & 15510 & $5 \%$ \\
\hline emergency & 35873 & $11 \%$ & illness & 15173 & $5 \%$ \\
\hline family & 35779 & $11 \%$ & economic & 15141 & $5 \%$ \\
\hline setting & 35535 & $11 \%$ & incidence & 14530 & $5 \%$ \\
\hline policy & 34369 & $11 \%$ & blood & 14010 & $4 \%$ \\
\hline experience & 33156 & $11 \%$ & variables & 13996 & $4 \%$ \\
\hline training & 31694 & $10 \%$ & guidelines & 13238 & $4 \%$ \\
\hline sample & 31611 & $10 \%$ & history & 12111 & $4 \%$ \\
\hline impact & 31578 & $10 \%$ & context & 11561 & $4 \%$ \\
\hline role & 31297 & $10 \%$ & Total & $4,144,458$ & \\
\hline
\end{tabular}

and "incidence" concepts. Accordingly, Table 4 suggests that closer inspection of the nursing concept confirms not only that nursing staffing and nursing role concepts predominate, far more than patient, family and community concepts. It also suggests that the nursing concept is marginal to more clinical disease and diagnostic concepts, as well as more technical epidemiological research concepts.

\section{Sentiment analysis}

In this study, sentiment analysis is used as an adjunct or supplementary analysis only. Figure 2 is a quadrant: the $\mathrm{x}$ axis is a measure of the extent of sentiment association (of any kind) and the $y$ axis is a measure of the proportion of that association that is positive (versus negative since we are dealing with only sentiment terms). The definition of the axes, adapted from the software output, is:

Relative Frequency: a measure of the conditional probability of the concept in a sub-period, given the category (in this case positive/negative sentiment), e.g. given we are looking at occurrences of positive or negative

Table 3 Counts and likelihood of the nursing concept, by study sub-period

\begin{tabular}{lll}
\hline Sub-period & Count & Likelihood \\
\hline $1995-1997$ & 4669 & $5 \%$ \\
$2001-2003$ & 6542 & $5 \%$ \\
$1998-2000$ & 5462 & $5 \%$ \\
$2004-2006$ & 8264 & $5 \%$ \\
$1992-1994$ & 3419 & $4 \%$ \\
$1989-1991$ & 2449 & $4 \%$ \\
$2007-2009$ & 9373 & $4 \%$ \\
$2010-2012$ & 11283 & $4 \%$ \\
2013 & 1991 & $3 \%$ \\
$1986-1988$ & 1055 & $3 \%$ \\
Total & 54,507 & \\
\hline
\end{tabular}

sentiment, how likely is it that the concept "patient" in the sub-period 1992-94 is mentioned?

Strength: a measure of the conditional probability of the category (in this case positive/negative sentiment) given the particular concept in a subperiod, e.g. given we are looking at occurrences of the concept "patient" in 1992-94, how often is it mentioned in positive versus negative sentiment, i.e. the 'strength' of the positive association [65]?

Understanding the central lines involves understanding the axes. The central lines that cross the graph simply suggest the middle lines of the quadrant. That is, for the $\mathrm{x}$ axis scale of $1 \%$ to $30 \%$, the midpoint is the point at which $15 \%$ of occurrences of positive or negative sentiment contain the concept "patient" in a sub-period. Given the $y$ axis is from $0-20 \%$, the midpoint on the $y$ axis is $10 \%$ or the point at which $10 \%$ of the content of a concept in a sub-period has positive associations (versus negative associations). Concepts in sub-periods located in the top right hand corner are therefore found more frequently with sentiment terms and are relatively more positive (which does not mean they are positive; that depends on the y scale). Concepts located in the bottom left hand corner are found less frequently with sentiment terms and are relatively more negative. Concepts that have insufficient sentiment associations of any kind do not, of course, appear.

Accordingly, the quadrant in Figure 2 visualises associations between a selection of 10 concepts: clinical, community, family, hospital, medical, nursing, patients, prevention, social, and treatment. The colour of the subperiod suggests concepts in that sub-period as indicated by the legend. The $\mathrm{x}$ or horizontal axis plots the relative frequency of sentiment associations of any kind, i.e., whether negative or positive, with a concept in a subperiod. The y or vertical axis plots the extent to which a given sub-period has positive associations, i.e., given a concept in a sub-period can often be found many times with sentiment associations (positive or negative), the 
Table 4 Counts and likelihood of paired co-occurrences for the nursing concept

\begin{tabular}{|c|c|c|c|c|c|}
\hline Nursing concept pair & Count & Likelihood & Nursing concept pair & Count & Likelihood \\
\hline home & 7045 & $25 \%$ & guidelines & 609 & $5 \%$ \\
\hline staff & 3734 & $16 \%$ & medical & 4202 & $5 \%$ \\
\hline role & 4711 & $15 \%$ & evidence & 1017 & $5 \%$ \\
\hline professionals & 3612 & $13 \%$ & individuals & 1340 & $4 \%$ \\
\hline practice & 7286 & $11 \%$ & use & 9567 & $4 \%$ \\
\hline work & 4878 & $11 \%$ & sample & 1385 & $4 \%$ \\
\hline education & 4891 & $11 \%$ & illness & 656 & $4 \%$ \\
\hline facilities & 1695 & $10 \%$ & national & 2027 & $4 \%$ \\
\hline knowledge & 2125 & $10 \%$ & system & 2410 & $4 \%$ \\
\hline satisfaction & 1507 & $9 \%$ & chronic & 654 & $4 \%$ \\
\hline training & 2941 & $9 \%$ & observed & 703 & $4 \%$ \\
\hline physicians & 2000 & $9 \%$ & users & 714 & $4 \%$ \\
\hline literature & 1288 & $8 \%$ & factors & 2023 & $4 \%$ \\
\hline experience & 2621 & $8 \%$ & follow-up & 606 & $4 \%$ \\
\hline questionnaire & 1710 & $8 \%$ & access & 1580 & $4 \%$ \\
\hline community & 4458 & $8 \%$ & effects & 804 & $4 \%$ \\
\hline setting & 2769 & $8 \%$ & significant & 2131 & $4 \%$ \\
\hline workers & 1289 & $8 \%$ & cancer & 1176 & $4 \%$ \\
\hline acute & 1247 & $7 \%$ & measures & 1812 & $4 \%$ \\
\hline development & 2712 & $7 \%$ & costs & 1895 & $4 \%$ \\
\hline needs & 3358 & $7 \%$ & procedures & 631 & $4 \%$ \\
\hline implementation & 2070 & $7 \%$ & variables & 514 & $4 \%$ \\
\hline context & 767 & $7 \%$ & control & 1649 & $3 \%$ \\
\hline psychiatric & 1212 & $7 \%$ & therapy & 750 & $3 \%$ \\
\hline management & 2996 & $6 \%$ & utilization & 701 & $3 \%$ \\
\hline delivery & 1528 & $6 \%$ & children & 2141 & $3 \%$ \\
\hline assessment & 1576 & $6 \%$ & history & 380 & $3 \%$ \\
\hline quality & 3388 & $6 \%$ & countries & 790 & $3 \%$ \\
\hline clinical & 5578 & $6 \%$ & prevention & 1213 & $3 \%$ \\
\hline environment & 1048 & $6 \%$ & population & 1564 & $3 \%$ \\
\hline research & 4271 & $6 \%$ & surgery & 874 & $3 \%$ \\
\hline participants & 2592 & $6 \%$ & risk & 1322 & $3 \%$ \\
\hline model & 2511 & $6 \%$ & age & 1524 & $3 \%$ \\
\hline hospital & 6481 & $6 \%$ & economic & 406 & $3 \%$ \\
\hline resources & 1667 & $6 \%$ & screening & 647 & $3 \%$ \\
\hline strategies & 1447 & $6 \%$ & test & 1036 & $3 \%$ \\
\hline program & 3489 & $6 \%$ & treatment & 1906 & $3 \%$ \\
\hline survey & 2494 & $6 \%$ & symptoms & 489 & $3 \%$ \\
\hline mental & 2720 & $6 \%$ & disease & 1268 & $2 \%$ \\
\hline social & 2568 & $6 \%$ & women & 1336 & $2 \%$ \\
\hline family & 1972 & $6 \%$ & diagnosis & 661 & $2 \%$ \\
\hline people & 3039 & $5 \%$ & medicine & 1179 & $2 \%$ \\
\hline intervention & 2379 & $5 \%$ & drug & 664 & $2 \%$ \\
\hline
\end{tabular}


Table 4 Counts and likelihood of paired co-occurrences for the nursing concept (Continued)

\begin{tabular}{|c|c|c|c|c|c|}
\hline improve & 2974 & $5 \%$ & infection & 479 & $2 \%$ \\
\hline rural & 1073 & $5 \%$ & blood & 267 & $2 \%$ \\
\hline review & 2118 & $5 \%$ & mortality & 412 & $2 \%$ \\
\hline planning & 1848 & $5 \%$ & hiv & 470 & $2 \%$ \\
\hline patients & 9888 & $5 \%$ & prevalence & 441 & $2 \%$ \\
\hline evaluation & 1835 & $5 \%$ & incidence & 251 & $2 \%$ \\
\hline physical & 897 & $5 \%$ & disorders & 415 & $2 \%$ \\
\hline impact & 1549 & $5 \%$ & men & 249 & $2 \%$ \\
\hline standard & 1064 & $5 \%$ & Total & 217002 & \\
\hline emergency & 1735 & $5 \%$ & & & \\
\hline policy & 1598 & $5 \%$ & & & \\
\hline local & 813 & $5 \%$ & & & \\
\hline
\end{tabular}

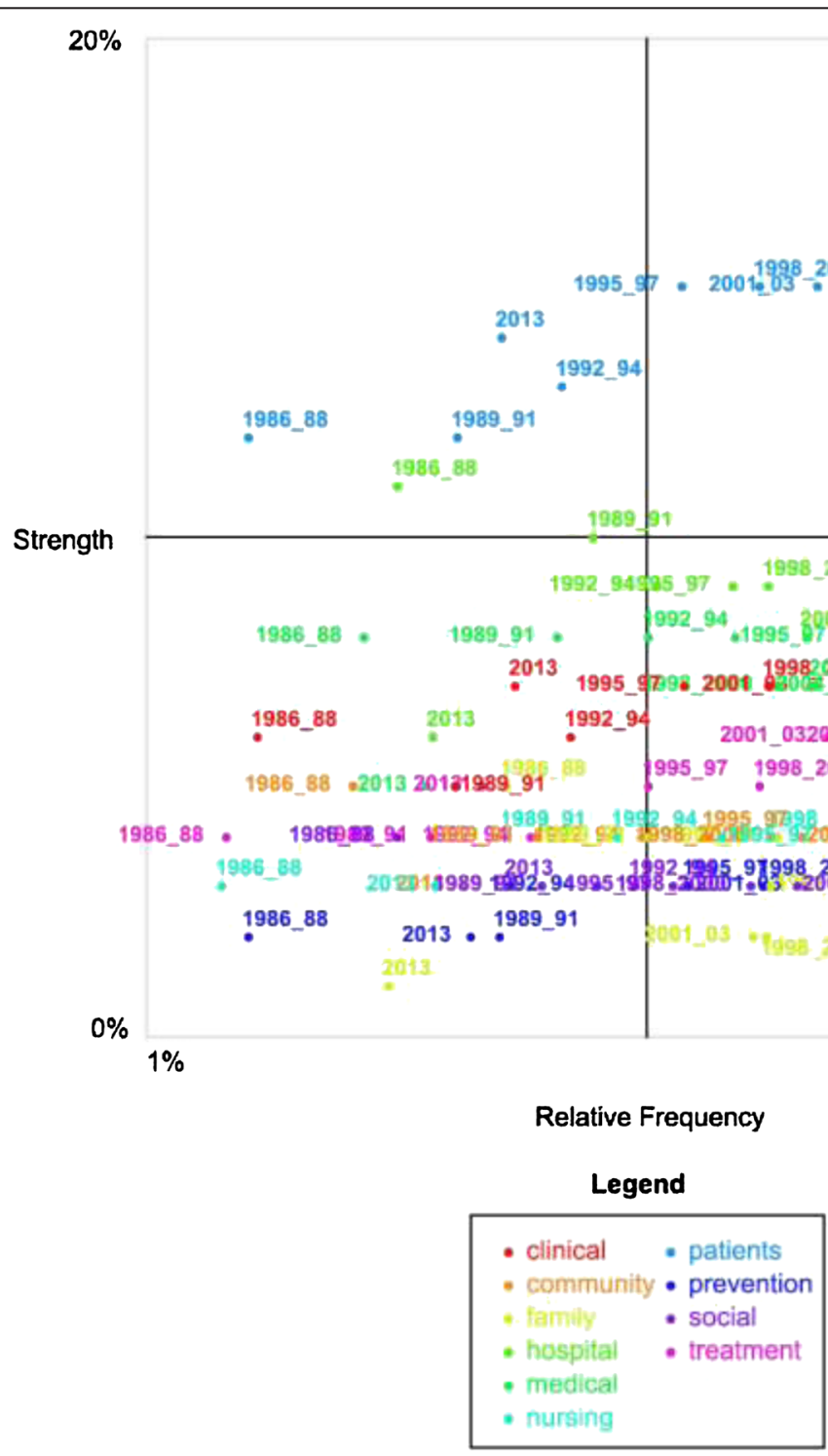

Figure 2 Sentiment analysis of selected concepts, by sub-period 1/1/1986 - 31/6/2013. 
proportion of those instances that are positive. The highest frequency for any of the selected concepts in a sub-period being found in text blocks with sentiment terms (negative or positive) is less than $30 \%$ (x axis). The proportion of positive to negative sentiment is less than $20 \%$ for all concepts in a sub-period (y axis).

Therefore, the y axis in Figure 2 suggests that "patients" is the most positive concept, followed by "hospital," "medical," "clinical," and "treatment." The other concepts are not so distinguishable in terms of proportion of positive sentiment; however, "family" tends to be the more negative concept, particularly since 1998. Accordingly, the quadrant suggests that in the discipline of health services research, as defined in PubMed abstracts, biomedical approaches, rather than community and family approaches have attracted greater proportions of positive sentiment. This is not the same as saying any of these concepts are generally positive: the midpoint of this scale of $10 \%$ means that only $10 \%$ of the sentiment associations are positive versus negative (i.e., $90 \%$ are negative). The generally negative language in research should be viewed as a feature of the genre of research which most often investigates problems in healthcare, rather than models of excellence. What are of interest here are the relativities: the fact that some concepts in some sub-periods are more positive than others. It is of interest to find that the more dominant concepts in the health services literature indicated by stage one of the analysis (patients, hospital, medical, clinical) tend to be the more positive concepts. Nursing, a concept that stages one and two suggested is less well connected to patient concepts, is also a less positive concept in these abstracts, when proportion of positive to negative sentiment is considered. This raises the question of whether the disassociation of nursing from patient care, observed in these abstracts in stages one and two, is somehow linked to the less positive nature of the construction of the nursing concept.

\section{Discussion}

The most important and contested element of nursing identity for the wider public may be the patientcentredness of nursing, though this concept has had relatively less attention in the nursing identity literature focussing on the academicisation and specialisation of nursing, as well as identity formation in student learning. If nursing identity is a critical part of healthcare reform agendas, health service research is actively working to construct nursing identity in particular ways. The field of computational text analytics, designed for the surveillance of large qualitative datasets, offers new opportunities for nursing to scrutinise and regulate how its identity is constructed in large research and other databases.
As health services research has grown in importance as part of the translational research movement, a number of techniques of nursing identity construction can be observed in its corpus of abstracts, indicative of the larger corpus of publications. Nursing appears constructed within quality assurance or service implementation or workforce development concepts. It appears relatively disconnected from patient, family or community care concepts. The patient concept, which is central to health services research, appears to have been appropriated within biomedical interventionist, cost utility and research measurement discourses. At the same time, health service research appears to have also positioned nursing in ways disconnected from technical clinical disease and diagnostic concepts as well as more technical epidemiological concepts. These other apparent appropriations of nursing identity are also potentially significant. For those who value an idea of nursing identity as being about patientcentred caregiving, the apparent disconnection of nursing from patient, family or community care concepts potentially threatens its relevance to its client communities. From this perspective, the disconnect of nursing from technical clinical concepts as well as more technical epidemiological concepts potentially jeopardises nursing identity in two other critical ways. That is, the disconnect of nursing from clinical concepts could be seen as suggesting a repositioning of nurses as subordinate to clinical experts. The disconnection of nursing from technical epidemiological concepts could also arguably be seen as locating nursing away from critical $21^{\text {st }}$ century research techniques of power for shaping policy-making, described in Porter's influential historical account of quantitative methodologies in policy-making: Trust in Numbers: The Pursuit of Objectivity in Science and Public Life [79].

The most ambiguous findings lie in the sentiment analysis. Given the well-established complexities and shortcomings of both human and computer-driven sentiment analyses [80], the sentiment analysis should be treated cautiously as an extension of stages one and two. Yet, in light of the findings of the earlier stages, it does raise important questions. Is the relative marginalisation of nursing in health services research, away from the central patient concept, as well as dominant clinical concepts, somehow caused by or leading to the use of the nursing concept in less positive ways? That is, put colloquially, is taking the care out of nursing linked to not caring about nursing?

Whatever the answer to this question, this study has offered indicative evidence of how the patient-centredness of nursing has fared in health service research captured by PubMed. It is precisely because health services research is a language space in which the nature of, and evidence for, healthcare is actively constructed that the general separation of the nursing concept from the patient concept is 
highly significant. The study could be seen as suggesting, in empirical quantifiable terms, a historic shift of nursing identity as direct caregiving. This shift can be seen in health services research represented in this study despite longstanding calls for nursing to be re-established as being about primary caregiving [81]. This study therefore suggests that health services evidence - itself a historical artefact that reflects cultural values and politicised language games - is working to create a quite different identity for nursing, at least in this database.

\section{Limitations}

The fact that the study has been limited to the database PubMed - albeit a large and influential database means its findings cannot be generalised to the entire discipline of health services, only health services research captured in PubMed. Accordingly, while the study allows one kind of "bird's eye" view of over a quarter of a century of health services research represented by PubMed, it does not offer an opportunity to examine why or how nursing identity has come to be constructed in these ways within the health services literature, at least as it is contained in this database. Computational text analytics allows the analyst to quantify the content of a large qualitative dataset but it is less helpful in understanding how such constructs came about. Other quantitative and qualitative methods such as multivariate analysis [34] and critical discourse analysis $[82,83]$, already used in nursing identity research [84], are needed to further explore the findings of this study. The contribution of countries and disciplines also are potentially fertile areas that lie outside the scope of the study. The value of the study therefore lies primarily in the way it offers the first scoping study of how health services research has positioned nursing identity in one particularly influential health sciences database.

\section{Conclusions}

This study raises some important questions for the discipline of health services research, as well as nursing advocacy, research and education. It suggests that a key evidence-base for health services - PubMed - tends not to position nurses as patient-centred caregivers. In so doing, this study contributes to broad popular and scholarly debates about whether the nursing professions need to actively reappropriate constructs of patient care as more central to nursing identity. In such debates, as the introduction suggested, the importance of education and training, and further re-interpretation of the academicisation and professionalization of nursing identity, is already acknowledged. Less well-known is whether and how the evidence-base for health services itself has positioned nurses as patient-centred caregivers. For those who agree that patient-centredness should be a part of nursing identity in practice, this study suggests that there is a need for the development of health services research into both the nature of the caring construct in nursing identity and its expression in practice. One way this could happen is through more dedicated programs of health services research in nursing disciplines, in ways that better articulate patient-centredness. More fundamentally, the study raises questions about whether health services research cultures even value the politically popular idea of nurses as patient-centred caregivers, as this growing scholarly discipline enters the $21^{\text {st }}$ Century, and whether they should.

\section{Competing interests}

The authors declare they have no competing interests. We have no interests whatsoever in the Australian company that sells Leximancer, nor have we had any involvement or interests in its design or development.

\section{Authors' contributions}

All authors contributed to the conceptualisation, design and development of the paper. LRG and SC wrote the final version of the paper following the untimely death of EB. Both SC and LRG read and approved the final manuscript. Much to our distress and her family, Dr. EB died last year, and is much missed. This paper would not have happened without her commitment and expertise.

\section{Acknowledgements}

This research received no specific grant from any funding agency in the public, commercial, or not-for-profit sectors. The research was part of core work undertaken by the authors as part of an informal collaboration. No funding agency had any role in the content or decision to submit this paper for publication.

\section{Author details}

'Wicking Dementia Research and Education Centre, University of Tasmania, Private Bag 143, Hobart, Tasmania 7001, Australia. ${ }^{2}$ School of Health Sciences, University of Tasmania, Locked Bag 1322, Launceston, Tasmania 7250, Australia.

Received: 23 November 2013 Accepted: 12 December 2014 Published online: 22 January 2015

\section{References}

1. Descartes R. Discourse on Method and Meditations on First Philosophy. USA: Hackett Publishing; 1998.

2. Freud S. The Basic Writings of Sigmund Freud (Psychopathology of Everyday Life, the Interpretation of Dreams, and Three Contributions To the Theory of Sex). New York: Random House; 1995.

3. Erikson E. Identity: Youth and Crisis. New York: Norton; 1968.

4. Bourdieu P. Distinction: A Social Critique of the Judgment of Taste. Oxford: Routledge; 1984

5. Foucault M. Discipline and Punish: The Birth of the Prison. Harmondsworth: Penguin; 1977.

6. Foucault M. Power/Knowledge: Selected Interviews and Other Writings 1972-1977. New York: Random House; 1981

7. Harré R, Moghaddam F, Cairnie T, Rothbart D, Sabat S. Recent advances in positioning theory. Theory Psychol. 2009;19(1):5-31.

8. Harré R, Moghaddam F. The Self and Others: Positioning Individuals and Groups in Personal, Political, and Cultural Contexts. Westport, CT: Praeger; 2003.

9. Harré R, van Langehove L. Positioning Theory. Oxford: Blackwell; 1999.

10. Hoeve YT, Jansen G, Roodbol P. The nursing profession: public image, self-concept and professional identity. A discussion paper. J Adv Nurs. 2014;70(2):295-309.

11. Hurley J. A qualitative study of mental health nurse identities: many roles, one profession. Int J Ment Health Nurs. 2009;18(6):383-90.

12. Brown J, Stevens J, Kermode S. Supporting student nurse professionalisation: the role of the clinical teacher. Nurse Educ Today. 2012;32(5):606-10. 
13. Johnson M, Cowin LS, Wilson I, Young H. Professional identity and nursing: contemporary theoretical developments and future research challenges. Int Nurs Rev. 2012;59(4):562-9.

14. Cowin LS, Johnson M, Wilson I, Borgese K. The psychometric properties of five Professional Identity measures in a sample of nursing students. Nurse Educ Today. 2013;33(6):608-13.

15. Worthington $M$, Salamonson $Y$, Weaver $R$, Cleary M. Predictive validity of the Macleod Clark professional identity scale for undergraduate nursing students. Nurse Educ Today. 2013;33(3):187-91.

16. Hercelinskyj G, Cruickshank M, Brown P, Phillips B. Perceptions from the front line: Professional identity in mental health nursing. Int J Ment Health Nurs. 2014;23(1):24-32.

17. Miskelly P, Duncan L: 'I'm actually being the grown-up now': leadership, maturity and professional identity development. J Nurs Manag 2013, doi:10.1111/jonm. 12030

18. Scott ES, Miles J. Advancing leadership capacity in nursing. Nurs Adm Q. 2013;37(1):77-82

19. Flynn M, McKeown M. Nurse staffing levels revisited: a consideration of key issues in nurse staffing levels and skill mix research. J Nurs Manag. 2009;17(6):759-66.

20. Tubbs-Cooley HL, Martsolf DS, Pickler RH, Morrison CF, Wardlaw CE. Development of a regional nursing research partnership for academic and practice collaborations. Nurs Res Pract. 2013;2013:473864.

21. Elliott $L$, Kennedy C, Raeside R: Professional role identity in shaping community nurses' reactions to nursing policy. J Nurs Manag 2013, doi:10.1111/jonm.12153.

22. Kreindler SA: The politics of patient-centred care. Health Expect 2013, doi:10.1111/hex.12087

23. Loder N: Dobson re-opens nurses' wounds. Times Higher Education, 9 October 1998 accessed at http://www.timeshighereducation.co.uk/109329. article on 12 January 2015.

24. Hall C: Young nurses too posh to wash. Telegraph. co.uk. May 2004. London: 2004 accessed at http://www.telegraph.co.uk/news/uknews/ 1461504/Young-nurses-too-posh-to-wash.html on 12 January 2015.

25. Gillett K. A critical discourse analysis of British national newspaper representations of the academic level of nurse education: too clever for our own good? Nurs Inq. 2012;19(4):297-307.

26. Ball E. A social purpose model for nursing. Nurs Forum. 2011;46(3):152-6.

27. Jasmine T. Art, science, or both? Keeping the care in nursing. Nurs Clin North Am. 2009:44(4):415-21.

28. Hobbs JL. A dimensional analysis of patient-centered care. Nurs Res. 2009:58(1):52-62.

29. Watson J, Smith MC. Caring science and the science of unitary human beings: a trans-theoretical discourse for nursing knowledge development. J Adv Nurs. 2002;37(5):452-61.

30. McKenna H. Nursing Theories and Models. London: Routledge; 1997.

31. McCance T, McKenna H, Boore J. Caring: dealing with a difficult concept. Int J Nurs Stud. 1997;34:241-8.

32. Leininger $M$. The phenomenon of caring: importance, research questions and theoretical considerations. In: Leininger M, editor. Caring: an Essential Human Need. Thorofare New Jersey: Slack; 1981. p. 2-15.

33. Morse J, Bottorff J, Neander W, Solberg S. Comparative analysis of conceptualisations and theories of caring. IMAGE: J Nurs Sch. 1991;23:119-27.

34. Watson R, Deary IJ, Lea A. A longitudinal study into the perceptions of caring among student nurses using multivariate analysis of the Caring Dimensions Inventory. J Adv Nurs. 1999:30(5):1080-9.

35. Lea A, Watson R, Deary IJ. Caring in nursing: a multivariate analysis. J Adv Nurs. 1998;28(3):662-71.

36. Watson R, Deary IJ, Lea A. A longitudinal study into the perceptions of caring and nursing among student nurses. J Adv Nurs. 1999;29(5):1228-37.

37. Watson $\mathrm{R}$, Lea $\mathrm{A}$. The caring dimensions inventory (CDI): content validity, reliability and scaling. J Adv Nurs. 1997;25(1):87-94.

38. Watson J. Assessing and Measuring Caring in Nurisng and Health. New York: Springer; 2001

39. Paley J. An archaeology of caring knowledge. J Adv Nurs. 2001;36:188-98.

40. Chaboyer W, Wallis M, Duffield C, Courtney M, Seaton P, Holzhauser K, et al. A comparison of activities undertaken by enrolled and registered nurses on medical wards in Australia: an observational study. Int J Nurs Stud. 2008;45(9):1274-84.
41. Colombo F, et al.: Help Wanted?: Providing and Paying for Long-Term Care, OECD Health Policy Studies, OECD Publishing. DOl: 10.1787/9789264097759-en

42. Hewitt J. Redressing the balance in mental health nursing education: arguments for a values-based approach. Int J Ment Health Nurs. 2009;18 (5):368-79.

43. Betts CE. Nursing and the reality of politics. Nurs Inq. 2009;16(3):261-72.

44. Cara CM, Nyberg JJ, Brousseau S. Fostering the coexistence of caring philosophy and economics in today's health care system. Nurs Adm Q. 2011;35(1):6-14.

45. Pilnick A, Dingwall R. On the remarkable persistence of asymmetry in doctor/ patient interaction: A critical review. Soc Sci Med. 2011;72(8):1374-82.

46. DH. Essence of Care. London: Department of Health; 2010.

47. NSWH. Essentials of Care. Sydney: NSW Health; 2011.

48. D'Antonio P. Cultivating constituencies: the story of the east Harlem nursing and health service, 1928-1941. Am J Public Health. 2013;103(6):988-96.

49. Horig H, Pullman W. From bench to clinic and back: Perspective on the 1st IQPC Translational Research conference. J Transl Med. 2004;2(1):44

50. loannidis J. Materializing research promises: opportunities, priorities and conflicts in translational medicine. J Transl Med. 2004;2(1):5. doi:10.1186/ 1479-5876-1182-1185.

51. Bell E. Great 21st Century debates about the usefulness of research: Can they help rural research? Rural Soc. 2008;18(1):3-16.

52. Fyffe T. Nursing shaping and influencing health and social care policy. J Nurs Manag. 2009;17(6):698-706.

53. Bird S, Klein E, Loper E. Natural Language Processing with Python. Sebastapol, CA: O'Reilly Media, Inc; 2009.

54. Cambria E, White B. Jumping NLP curves: a review of natural I anguage processing research [review article]. Comput Intell Mag, IEEE. 2014;9(2):48-57.

55. Kern ML, Eichstaedt JC, Schwartz HA, Park G, Ungar LH, Stillwell DJ, et al. From "Sooo excited!!!" to "So proud": using language to study development. Dev Psychol. 2014;50(1):178-88.

56. Bui DD, Zeng-Treitler Q. Learning regular expressions for clinical text classification. J Am Med Inform Assoc. 2014;21(5):850-7.

57. Forbush TB, Gundlapalli AV, Palmer MN, Shen S, South BR, Divita G, et al. Sitting on pins and needles": characterization of symptom descriptions in clinical notes. AMIA Summits Transl Sci Proc AMIA Summit Transl Sci. 2013;2013:67-71

58. Cole TS, Frankovich J, lyer S, Lependu P, Bauer-Mehren A, Shah NH. Profiling risk factors for chronic uveitis in juvenile idiopathic arthritis: a new model for EHR-based research. Pediatr Rheumatol. 2013;11(1):45. doi:10.1186/1546-0096-11-45

59. Carrell DS, Halgrim S, Tran DT, Buist DS, Chubak J, Chapman WW, et al. Using natural language processing to improve efficiency of manual chart abstraction in research: the case of breast cancer recurrence. Am J Epidemiol. 2014;179(6):749-58.

60. Poulin C, Shiner B, Thompson P, Vepstas L, Young-Xu Y, Goertzel B, et al Predicting the risk of suicide by analyzing the text of clinical notes. PLOS One. 2014;9(1):e85733.

61. Watts BV, Shiner B, Zubkoff L, Carpenter-Song E, Ronconi JM, Coldwell CM. Implementation of evidence-based psychotherapies for posttraumatic stress disorder in VA specialty clinics. Psychiatr Serv. 2014;65(5):648-53.

62. Chary M, Park EH, McKenzie A, Sun J, Manini AF, Genes N. Signs \& symptoms of dextromethorphan exposure from YouTube. PLoS One. 2014;9(2):e82452

63. Imler TD, Morea J, Imperiale TF. Clinical decision support with natural language processing facilitates determination of colonoscopy surveillance intervals. Clin Gastroenterol Hepatol. 2014;12(7):1130-6.

64. Halper F. Predictive analytics: the Hurwitz victory index report. In: Hurwitz Victory Index. Needham, MA, USA: Hurwitz \& Associates; 2011

65. Leximancer Manual version 4, 2011. https://www.leximancer.com.

66. Smith AE, Humphreys MS. Evaluation of unsupervised semantic mapping of natural language with Leximancer concept mapping. Behav Res Methods Fig. 2006;38(2):262-79.

67. Baker SC, Gallois C, Driedger SM, Santesso N. Communication accommodation and managing musculoskeletal disorders: doctors' and patients' perspectives. Health Commun. 2011;26(4):379-88.

68. Cretchley J, Gallois C, Chenery H, Smith A. Conversations between carers and people with schizophrenia: a qualitative analysis using leximancer. Qual Health Res. 2010;20(12):1611-28. 
69. Hepworth N, Paxton SJ. Pathways to help-seeking in bulimia nervosa and binge eating problems: a concept mapping approach. Int J Eating Disord. 2007;40(6):493-504.

70. Hewett DG, Watson BM, Gallois C, Ward M, Leggett BA. Intergroup communication between hospital doctors: implications for quality of patient care. Soc Sci Med. 2009;69(12):1732-40.

71. Kuyini AB, Alhassan A-RK, Mahama FK. The Ghana community-based rehabilitation program for people with disabilities: what happened at the end of donor support? J Soc Work Disabil Rehabil. 2011;10(4):247-67.

72. Kyle GJ, Nissen L, Tett S. Perception of prescription medicine sample packs among Australian professional, government, industry, and consumer organizations, based on automated textual analysis of one-on-one interviews. Clin Ther. 2008;30(12):2461-73.

73. Pakenham Kl, Tilling J, Cretchley J. Parenting difficulties and resources: the perspectives of parents with multiple sclerosis and their partners. Rehabil Psychol. 2012;57(1):52-60.

74. Travaglia JF, Westbrook MT, Braithwaite J. Implementation of a patient safety incident management system as viewed by doctors, nurses and allied health professionals. Health (London, England: 1997). 2009;13(3):277-96.

75. Friedman A, Smiraglia R. Nodes and arcs: concept map, semiotics, and knowledge organization. J Doc. 2013;69(1):27-48.

76. Saussure F. Course in General Linguistics. London: Duckworth; 1916.

77. Chi DL, Tucker-Seeley R. Gender-stratified models to examine the relationship between financial hardship and self-reported oral health for older US Men and women. Am J Public Health. 2013;103(8):1507-15.

78. Understanding Displays and Outputs [https://www.leximancer.com/faq/ display_and_output.html]

79. Porter T. Trust in Numbers: The Pursuit of Objectivity in Science and Public Life. Princeton: Princeton University Press; 1995.

80. Pang B, Lee L. Opinion mining and sentiment analysis. Foundations Trends Inf Retrieval. 2008;2(1-2):1-135

81. Hey K. Occupational changes in nursing: the situation of enrolled nurses. J Adv Nurs. 2004;45(4):360-70.

82. Fairclough N. Discourse and Social Change. Cambridge: Polity Press; 1992.

83. Fairclough N. Critical Discourse Analysis. London: Longman; 1995.

84. Kelly J, Fealy GM, Watson R. The image of you: constructing nursing identities in YouTube. J Adv Nurs. 2012:68(8):1804-13.

\section{Submit your next manuscript to BioMed Central and take full advantage of:}

- Convenient online submission

- Thorough peer review

- No space constraints or color figure charges

- Immediate publication on acceptance

- Inclusion in PubMed, CAS, Scopus and Google Scholar

- Research which is freely available for redistribution 